\title{
CONTRIBUIÇÕES DA \\ PEDAGOGIA NO CREAS: \\ ENFRENTAMENTO E PREVENÇÃO \\ DE VIOLÊNCIA SEXUAL CONTRA \\ CRIANÇAS E ADOLESCENTES
}

Magna Terra Jordão

Luana Frigulha Guisso

\section{INTRODUÇÃO}

Pensar na função do pedagogo fora do contexto escolar ainda é uma dificuldade até mesmo para este profissional em delimitar e fazer reconhecido seu papel e atuação. A atuação do pedagogo se encontra prevista dento Política Nacional de Assistência Social, regulamentada pela Resolução nº 17, de 20 de Junho de 2011, tanto nos Centros de Referência em Assistência Social (CRAS) e nos Centros de Referência Especializados em Assistência (CREAS), no desenvolvimento de ações reflexivas e emancipação de pessoas, para que possam militar por seus direitos (BRASIL, 2011).

Cumpre ressaltar que a Resolução ${ }^{\circ} 17$ de 20 de junho de 2011 seguindo a Norma Operacional Básica do Sistema Único de Assistência Social (NOB/SUAS) (2011, p.33) que recomenda: "parâmetros para a seleção de profissionais, a partir das especificidades locais, do conhecimento das necessidades de seus usuários e da disponibilidade de profissionais na região". Quando a inserção desde profissionais não for realizada por meio de concurso público a mesma deve então ser feita por meio de processos seletivos com o rigor e devida transparência seguindo os parâmetros legais, para contratação de mão de obra qualificada para atender o público e as demandas cotidianas presentes nos equipamentos do SUAS.

Os Centros de Referência Especializada em Assistência Social (CREAS), compõem rede de serviços que integram a Política de Assistência Social, são unidades públicas que prestam atendimentos famílias e pessoas que estão em situação de risco social ou tiveram seus direitos violados. No Brasil constituem como um dos principais serviços no acolhimento a crianças e adolescentes vítimas de violência sexual.

Conforme as diretrizes do Estatuto da Criança e Adolescente (ECRIAD) os CREAS devem oferta escuta qualificada e acompanhamento dos casos de crianças e adolescentes vítimas de violência sexual. Este equipamento faz parte do Sistema Único de Assistência Social, por sua vez, os CREAS são responsáveis pela proteção social de média complexidade (BRASIL, 2005). Dessa forma, o CREAS pode ser definido 
como um serviço de atendimento e enfrentamento à violência sexual contra crianças e adolescentes que visa à proteção e à garantia integral de direitos da população infanto-juvenil.

O CREAS trata-se de "uma unidade pública que se constitui como polo de referência, coordenador e articulador da proteção social especial de média complexidade" (BRASIL, 2011, p. 74). Esses equipamentos socioassistenciais realizar abordagens sociais, visando a proteção e atendimentos especializados para família e indivíduos, há jovens em cumprimento de medidas socioeducativas, idosos, pessoas com deficiências e pessoas em situação de rua. A equipe multidisciplinar é composta por psicólogos e assistentes sociais, advogados, educadores sociais, auxiliares administrativos e de serviços gerais (ANTUNES, SILVA, 2017).

Conforme na Lei de Diretrizes e Bases (LDB) nº. 9394, aprovada em 1996. No Artigo $1^{\circ}$ está expresso que "A Educação abrange os processos formativos que se desenvolvem na vida familiar, na convivência humana, no trabalho, nas instituições de ensino e pesquisa, nos movimentos sociais e organizações da sociedade civil e nas manifestações culturais" (BRASIL, 1996).

Nesse sentido o pedagogo possui uma formação voltada para desenvolver processos de aprendizagem, utilizando de tecnologias e metodologias específicas para este propósito (GOMES, et. al, 2018). Caliman (2011, p. 237) salienta que "a criatividade do brasileiro em inventar novos processos educativos fora da escola é evidente na grande quantidade de instituições e atividades não formais voltadas para a educação". A participação do pedagogo na Política de Assistência Social pode muito contribuir para melhor funcionamento do serviço. Na esteira deste pensamento Libâneo (2005, p. 27) assinala que:

\footnotetext{
De fato, vem se acentuando o poder pedagógico de vários agentes educativos formais e não formais. Ocorrem ações pedagógicas não apenas na família, na escola, mas também nos meios de comunicação, nos movimentos sociais e outros grupos humanos organizados, em instituições não escolares. Há intervenção pedagógica na televisão, no rádio, nos jornais, nas revistas, nos quadrinhos, na produção de material informativo, tais como livros didáticos e paradidáticos, enciclopédias, guias de turismo, mapas, vídeos e, também, na criação e elaboração de jogos, brinquedos.
}

De acordo com Pereira (2019) o fazer pedagógico deste profissional deve percorrer por vários campos de atuação para conhecer métodos de promover conhecimento. Deste modo, as diretrizes curriculares dos cursos de pedagogia no Brasil precisam obedecer as normativas propostas pelo Conselho Nacional de educação (CNE) que no ano de 2005, determina em seu art $4^{\circ}$, inciso IV, que os pedagogos devem ser habilitados e receber o conhecimento durante sua formação para atuar em "em espaços escolares e não-escolares, na promoção da aprendizagem de sujeitos em diferentes fases do desenvolvimento humano, em diversos níveis e modalidades processo educativo".

Ainda no que tange as atividades desempenhadas pelo profissional de pedagogia fora de instituições escolares, cumpre ressaltar que o referido documento ainda estabelece como atribuições deste profissional:

[...] atuar com ética e compromisso com vistas à construção de uma sociedade justa, equânime, igualitária; trabalhar, em espaços escolares e não escolares, na promoção da aprendizagem de sujeitos em diferentes fases do desenvolvimento humano, em diversos níveis e modalidades do processo educativo; identificar problemas socioculturais e educacionais com postura investigativa, integrativa e prepositiva em face de realidades complexas, com vista a contribuir para superação de exclusões sociais, étnico-raciais, econômicas, culturais, religiosas, políticas e outras (BRASIL, 2005, p.131).

Nesse sentido, Barros (2012, p. 08) assinala que atuação do pedagogo no campo da assistência social é complexa pois o profissional torna-se responsável em "promover uma educação integral que venha atender 
a todos que estão ali presentes no meio social (na rua), visando o pleno desenvolvimento da pessoa para a construção e prevalência da cidadania”. Segundo o autor a pedagogia social surge como uma alternativa político-pedagógica consiste em umas das áreas de atuação do pedagogo que se encarrega de estudar questões das sociedades interligadas ao desenvolvimento humano, contudo nem todos os profissionais da área estão habilitados para essa função.

Na esteira deste pensamento, Araujo et. al (2014, p. 07) adverte que:

Ao contrário do que muitos pensam a pedagogia social não é simplesmente entretenimento, mas dispõe de objetivos específicos a serem alcançados no lugar que está implantado. Como percebemos ao observar trabalhos desenvolvidos nestas organizações a atuação na pedagogia social não difere em termo didático da pedagogia formal, pois esta procura em sua intervenção identificar os problemas daquela comunidade e buscar alternativas para superá-los.

Nas palavras de Araújo (2013), “essa deve ser uma relação de pertencimento capaz de compreender educador e educando como partes integrantes de uma mesma realidade, não fazendo mais sentido a existência de um sem o outro". Em termos similares Graciani (2014) que a pedagogia social possui seu caráter libertador, pois a educação não é um componente da vida que pertence exclusivamente a escola, a educação se faz onde existe vida, ali sempre existe uma oportunidade de aprender.

O presente capítulo tem por objetivo problematizar possíveis intervenções do pedagogo atuante no CREAS na prevenção e enfrentamento de violência sexual contra crianças e adolescentes

\section{METODOLOGIA}

Utilizando-se da análise qualitativa para responder ao objetivo deste estudo sobre as contribuições do pedagogo nos CREAS foram entrevistadas cinco pedagogas do sexo feminino que atuam neste equipamento da assistência social. Entre as entrevistadas quatro possuem mestrado e uma é especialista. No que se refere ao tempo de atuação três ressaltaram atuarem a mais de dez anos na assistência social apenas no CREAS, e as outras duas mencionaram terem um ano de atuação neste campo. Foram feitas apenas cinco perguntas como consta no roteiro. As respostas deram origem a três categorias temáticas que serão apresentadas a seguir.

\subsubsection{Atuação do pedagogo dentro da Política Nacional de Assistência Social}

Nas últimas décadas as políticas sociais no Brasil tomaram novos horizontes expandindo seus programas e serviços, com isso faz-se necessário também ampliar seus equipamentos CRAS e CREAS, lembrando que o primeiro se refere a proteção básica na prevenção e fortalecimento de vínculos, por sua vez o segundo que é nosso objeto de estudo só é acionado quando ocorre a violação direitos, tais como o abuso e violência sexual contra crianças e adolescentes, que passam a serem inseridas na rede proteção.

Com o passar do tempo visando aprimoramento dos equipamentos das políticas públicas viu-se a necessidade de inserir neste contexto outros profissionais na linha de frente para operacionalizar os serviços propostos na política nacional de assistência social, entre estes o pedagogo. Contudo desde sua inserção 
ainda pouco se fala na literatura sobre este profissional neste campo de atuação. O que faz o pedagogo no CREAS? Este questionamento tornou-se analisador para tecer esta categoria temática, veja as narrativas a seguir:

\begin{abstract}
Quando se fala em pedagogo logo se pensa em escola, porém a pedagogia é uma ciência que possui muitos campos de atuação como empresas, escolas, hospitais, ONGS, e também nos equipamentos do SUAS. Pensava-se que a assistência social era da assistente social, não assistência social é para o povo. O pedagogo no CREAS ele atua em várias frentes, na de violência contra a criança, contra o idoso, contra a mulher, contra as pessoas com deficiência, ou seja, todos aqueles que tem seus direitos violados. O pedagogo no CREAS também trabalha nos serviços de medidas socioeducativas. Nosso trabalho no CREAS baseia-se nas em promover os grupos reflexivos, ações educativas, organizar eventos, palestras, acolhimentos também. (PEDADAGOGA 1).
\end{abstract}

O pedagogo desenvolve a participa de todos os projetos do CREAS quando solicitado, atuando em todas as frentes que houver demandas (PEDADAGOGA 2).

Sobre este aspecto Silva e Cleone (2019, p. 922) assinalam que o CREAS se constitui "como órgão responsável por apresentar às vítimas nele atendidas os direitos aos quais fazem jus". Contudo aos autores reconhecem as fragilidades existentes na rede de proteção a mulher em situação de violência, a falta de articulação e intersetorialidade impossibilita a realização de outros trabalhos profissionais, entre estes o pedagogo, como nos mostra a narrativa a seguir:

O trabalho pedagogo no CRAS ou no CREAS, na assistência de modo geral é feito em rede, a gente trabalha em rede, desenvolvendo palestras, contribuindo para implementação da política a meu ver é isso que o pedagogo faz na assistência social (PEDAGOGA 5)

Nas palavras de Leal e Selow (2015) o conceito de rede consiste em "uma estrutura aberta, com fim de se expandir e de se comunicar dentro da própria rede compartilhando as mesmas informações e objetivos". As redes são dispositivos que potencializam o trabalho intersetorial e possibilitam inovações. Um dos principais objetivos de uma rede e promover a aprendizagem social, produzir significados, compartilhar conhecimentos. Para Vieira e Hasse (2017): "Sua efetivação depende do trabalho de diversos atores nos âmbitos do governo e da sociedade, da inserção de conhecimentos específicos e novas tecnologias tanto na saúde quanto em outros setores, governamentais e não governamentais".

O pedagogo desenvolve diversas ações educativas, junto aos demais técnicos, elaborando projetos, palestras (PEDAGOGA 3).

Nesse sentido o trabalho do pedagogo na assistência social ao desenvolver ações educativas, consiste em levar educação popular possibilitando aos usuários do serviço se apropriarem dos seus direitos, para Gomes, Rainha e Hernandes (2018) o conhecimento materializa-se como um dispositivo de mudanças sociais que nos possibilita enfrentar as desigualdades sociais, pois existe uma grande parcela da população que deixa de ter acesso aos seus direitos por desconhecimento estando mais sujeitos a violações, pois quando essas acontecem não sabem a quem recorrer.

O trabalho do pedagogo na assistência social é mais que palestras, ou fazer cartazes, é contribuir para que aquelas pessoas que tiveram seus direitos violados, possam receber o conhecimento de lutar por eles, trabalhar também a reinserção social dos adolescentes em conflito com a lei que cumprem medidas de 
Nota-se que o pedagogo torna-se aquele que em parceria com os demais técnicos visa construir estratégias, adequar linguagens para abordar temas complexos, como a violência sexual contra crianças e adolescentes, assim como mulheres que sofreram violências domésticas, o profissional precisa conhecer a legislação do SUAS até mesmo para saber seus limites e fazer devidos encaminhamentos.

No que diz respeito as medidas socioeducativas o pedagogo contribui articulando com a escola a reinserção deste usuário, dentro do sistema de rede municipal ou estadual de ensino, acompanhando sua frequência escolar como requisito medida imposta legalmente (HERNANDES, 2019). Uma vez que este acompanhamento se faz necessário para o aluno tenha o acesso à educação sem ser descriminado por sua situação, tendo em visto que os preconceitos contra este público são múltiplos, tanto da sociedade, assim como da própria escola em receber este aluno, pelo fato pedagogo ser um profissional que possui uma formação mais voltadas para o processo de ensino aprendizagem.

\subsubsection{O pedagogo diante da violência sexual contra crianças e adolescentes}

A violência sexual contra crianças e adolescentes é um fenômeno mundial começou a ser enfrentada como problema de cunho social na última década do século XX. Deste modo, o equipamento CREAS dentro do Política Nacional de Assistência Social veio para atender estas demandas de violação de direitos de crianças e adolescentes. O trabalho do CREAS é sempre realizado com base na rede de proteção com o conselho tutelar e sistema judiciário.

Nesse sentido o pedagogo possui um importante papel na prevenção e enfrentamento da violência sexual contra crianças e adolescentes dentro do CREAS, nas narrativas a seguir os pedagogos falam como é feito o seu trabalho nesse contexto:

A violência sexual contra crianças e adolescentes é uma realidade do CREAS nós sempre realizamos campanhas de prevenção no dia 18 de maio, vamos as escolas e abordamos os temas de maneira lúdica, de acordo com a faixa etária de cada turma (PEDAGOGA 1).

O 18 de maio é o dia nacional de enfrentamento a violência sexual de crianças e adolescentes o uso do lúdico permite criar um contexto no qual a criança ou até mesmo as adolescentes expõe seus sentimentos, demostrando as facetas de seu passado, presente e futuro. "Entretanto, passado, presente e futuro fundem-se e confundem-se durante a brincadeira, pois o estágio de desenvolvimento cognitivo em que se encontram não permite completa compreensão desta tríade" (GIACOMELO, MELO, 2011).

$\mathrm{O}$ abuso sexual pode trazer sérios agravos em saúde mental para a vida do indivíduo, que tendem a se manifestar com maior intensidade na vida adulto quando os sintomas reprimidos durante a infância se manifestam por meio de doenças psicossomáticas. A maioria dos pesquisadores concorda que o abuso sexual infantil é facilitador para o aparecimento de psicopatologias graves, prejudicando a evolução psicológica, afetiva e social da vítima. (ROMARO; CAPITÃO, 2007). Sobre este aspecto Prado (2004) advertem que:

Os sintomas atingem todas as esferas de atividades, podendo ser simbolicamente a concretização, ao nível do corpo e do comportamento, daquilo que a criança ou o adolescente sofreu. Ao passar por uma 
experiência de violação de seu próprio corpo, elas reagem de forma somática independentemente de sua idade, uma vez que sensações novas foram despertadas e não puderam ser integradas (PRADO, 2004 p. 64).

A violência sexual contra crianças e adolescentes pode afetar toda estrutura familiar, principalmente quando abuso é cometido por alguém do seio familiar, podendo ocasionar outra violência, pois muitos pais cometem homicídios ao descobrirem que seus filhos passaram essa atrocidade. Ou até mesmo quando o abuso é cometido por um pai, uma mãe, tio, tia, avô, avó, primo ou primas, ou entre irmãos. Quando a violência sexual ocorre no âmbito familiar, estendendo-se da família biológica à adotiva ou socioafetiva, denomina-se abuso sexual intrafamiliar (NAKATANI, 2012). Quando este ato é praticado é por indivíduos que não possuem relações de parentesco ou de conhecimento com a criança, o referido autor classifica como extrafamiliar.

As crianças e adolescentes na maioria dos casos são ameaçadas, pelo agressor. Então a vítima se cala com medo de algo acontecer com os familiares, pois o medo é um operador político, também é um dispositivo que produz formas de sujeição e subjetivação (HERNANDES, GENTIL LI, 2018). "A questão do trauma psíquico, evidentemente, está no cerne da situação do abuso sexual” (GABEL, 1997).

Neste sentido também é preciso considerar a "vergonha de falar de uma vida de sofrimento, de humilhação e principalmente, quando o que se fala carrega questões de ordem sexual é um dificultador para a certificação do ocorrido" (MATIAS, s.d.). Há um trabalho complexo a ser realizado neste sentido as narrativas mencionam que:

O abuso sexual meche com toda estrutura familiar, então precisamos fazer um trabalho realmente de rede e algo muito sigiloso para que não haja estigmatização (sic) tanto da família, quanto da criança. Nesse sentido buscamos criar grupos de apoio a famílias que vivenciaram um abuso sexual, e também fazemos o trabalho de prevenção com a campanha do faça bonito em maio (PEDAGOGA 2).

Habigzang (2000) afirma que pais que passaram esta experiência demoram um longo processo até se reorganizarem, surgindo sentimento de culpa. O autor também aponta em seus estudos os casos de negligências e outros fatores associados como transtornos psiquiátricos e uso de álcool e outras drogas e. Outra fatalidade também vivenciadas por profissionais do CREAS é quando a família passa a responsabilizar a criança ou adolescente, pela violação querendo isentar o agressor perante a lei pelo ato cometido. Deste modo uma pedagoga menciona que:

Para mim é um dos meus trabalhos mais difíceis a serem realizados, fazemos um trabalho de rede, pois muitas vezes a criança é institucionalizada, então precisamos acompanhar esse processo, as campanhas do Faça bonito que fazemos em maio é um trabalho muito importante para o pedagogo quando vamos as escolas, nos bairros abordar o tema. (PEDAGOGA 3).

As ações intersetoriais realizadas entre escola e CREAS são imperiosas na prevenção e enfrentamento da violência sexual contra crianças e adolescentes. Neste sentido, enfrentar a violência sexual requer: "a efetiva integração de diferentes setores como saúde, segurança, justiça e educação, bem como o envolvimento da sociedade civil organizada. Infelizmente, não se tem uma atuação da educação preconizando a prevenção e a intervenção. ” (INOUE, RISTUM, 2008). 
O Faca bonito é o principal projeto que desenvolvo dentro da assistência social, que o CREAS realiza para prevenir os abusos, ensinando as crianças e adolescente como base na sua linguagem a se defenderem e também onde buscar socorro, utilizamos muito um filme chamado o Silêncio de Lara (PEDAGOGA 4).

O uso da linguagem apropriada se faz preciso, pois a criança não possui a mesma compreensão do adolescente. Com isso e pedagogo com base nas teorias do desenvolvimento humano e outros conhecimentos adquiridos em sua formação, para identificar qual a melhor linguagem para se utilizar de acordo a cada faixa etária. O Silêncio de Lara é um curta que narra a história de uma adolescente que era abusada sexualmente pelo próprio avô desde a infância, com isso torna-se um dispositivo que pode disparar questões sensibilizar familiares e educadores e também os próprios adolescentes onde procurar auxílio.

\footnotetext{
É uma triste realidade, o trabalho do pedagogo no CREAS é muito pesado, trabalhamos com casos pesados, dentro do CREAS não é um ambiente escolar, mas aqui resolvemos muitos dos problemas que a escola não está preparada para resolver entre essas a questão do abuso sexual. Então o pedagogo cria uma ponte entre as políticas da educação e de assistência social. O Faça bonito é nosso principal projeto que o pedagogo desenvolve tanto na prevenção, quanto enfrentamento da violência sexual, do abuso e também da exploração sexual, que é muito frequente nas comunidades do interior, o pai alcoolista, ou a mãe prostituir a filha em troca de drogas. Já tivemos casos assim, então com O Faça Bonito dizemos as crianças e adolescentes que elas não estão sozinhas que existe uma rede de proteção (PEDAGOGA 5).
}

Segundo Hofling (2001, p.31), "as políticas sociais se referem a ações que determinam o padrão de proteção social implementado pelo Estado, com o objetivo de diminuir a desigualdade socioeconômica, através da redistribuição dos benefícios sociais". Visando alcançar esses objetivos e mais que necessário que as políticas públicas dialoguem entre si, que os profissionais nelas desenvolvidos estejam dispostos a se unir neste propósito e não cair no comodismo, negando seu papel e responsabilidades, previstos na constituição e no ECRIAD, na garantia de direitos de crianças e adolescentes.

Desse modo assumir o seu compromisso social, não fechando os olhos para essa realidade que se configura como uma ameaça a todas as crianças e adolescentes que se trata do abuso sexual, outra questão importante a ser destacada na fala desta pedagoga refere-se à exploração sexual.

De acordo com Pedersen, Dias e Oliveira (2018) o Brasil durante muito foi visto como centro do turismo sexual, crianças e adolescentes tornaram-se mercadoria para turistas. O CREAS trona-se um dos grandes avanços das políticas sociais unidas a políticas de educação para enfrentar essa expressão da questão social, que incide sobre os seguimentos mais vulneráveis.

Hernandes (2020) relata que muitas meninas são utilizadas pelos pais ou responsáveis legais como moeda de troca para ter acesso ao uso de substâncias psicoativas, com isso a drogadição se torna uma questão de risco. Nestes casos atuação do CREAS é retirar esta criança ou adolescente do ambiente de risco, o pedagogo é um dos profissionais que participa do acolhimento em prol da garantia dos direitos dentro do equipamento do CREAS.

\section{CONSIDERAÇÕES FINAIS}

Observou-se também que atuação dos pedagogos dentro dos CREAS ainda é algo recente, nem todos os profissionais compreendem o papel deste profissional sendo a ele delegado funções que nem sempre 
condizem com a sua verdadeira atuação, tais como serviços administrativos, ou apenas aquele que elabora cartazes. O pedagogo embora tradicionalmente seja visto como um profissional restrito ao ambiente escolar pode exercer sua profissão em muitos outros contextos e espaços para além dos escolares.

Dentro da assistência social, enfatizando especificamente o CREAS nosso local de estudos o pedagogo atua conforme as diretrizes da Política Nacional de Assistência Social, desenvolvendo junto aos outros técnicos do serviço ações intersetorias e ações educativas, que venham promover o conhecimento de seus direitos aos usuários dos serviços sócio assistenciais, desprovidos de conhecimento. O trabalho do pedagogo nos CREAS pode ser de acordo a Lei orgânica de cada município, pois cada CREAS se constitui como um território singular com demandas diferentes. O mesmo pode ser divido por frentes de trabalhos, ou equipes.

Assim como possibilitou identificar violações direitos em crianças vítimas de violência sexual atendida pela CREAS do Município de Presidente Kennedy; descrever características comportamentais de crianças e adolescentes vítimas de violência sexual. 


\section{REFERÊNCIAS BIBLIOGRÁFICAS}

ANTUNES, Scheila Espinola; SILVA, Otávio Guimarães da. Entendimentos e concepções dos profissionais do Creas sobre o papel do esporte nas medidas socioeducativas PSC e LA. Revista Brasileira de Ciências do Esporte. 2018. Dísponivel em : https://www.scielo.br/scielo.php?script=sci_arttext\&pid=S0101-32892018000200170. Acesso em: 10 de Junho de 2018.

BRASIL. Relatório de monitoramento do plano nacional de enfrentamento da violência sexual contra crianças e adolescentes. 2013-2018. p. 91. 2018.

CANZONIERI, A. M. Metodologia da Pesquisa Qualitativa na Saúde. 2. Ed. Petrópolis-RJ, 2011.

FLORENTINO, Bruno Ricardo Bérgamo. As possíveis consequências do abuso sexual praticado contra crianças e adolescentes. Fractal, Rev. Psicol. Rio de Janeiro , v. 27, n. 2, p. 139-144; 2015. Disponível em: <http://www. scielo.br/scielo.php?script=sci_arttext\&pid=S1984-02922015000200139\&lng=en\&nrm=iso>. Acesso em: 12 Mar. 2020 .

GAIO, R.; CARVALHO, R.B.; SIMÕES, R. Métodos e técnicas de pesquisa: a metodologia em questão. In: GAIO, R. (org.). Metodologia de pesquisa e produção de conhecimento. Petrópolis, Vozes, 2008.

GODOI, Marcos Roberto; NEVES, Luciene. Corpo, violência sexual, vulnerabilidade e educação libertadora no filme "Preciosa: uma história de esperança". Interface (Botucatu), Botucatu , v. 16, n. 41, p. 409-422, 2012. Disponível em: <http://www.scielo.br/scielo.php?script=sci_arttext\&pid=S1414-32832012000200010\&lng=en\&nrm=iso $>$. Acesso em: 12 Mar. 2020.

HERNANDES, L. F. Relatório Técnico de atendimentos psicológicos a pessoas em privação de Liberdade. IBRASC. 2017.

HERNANDES, L. F. Internação Compulsória e a vida em cena. [Mestrado em Políticas Públicas e Desenvolvimento Local]. Vitória: Escola Superior de Ciências da Santa Casa de Misericórdia de Vitória - EMESCAM, 2016.

HERNANDES, L. F.; GENTILLI, R. M. Lettres de cacht em dias atuais: pensando a internação compulsória, entre políticas e clínicas possíveis. In: Jandesson Mendes Coqueiro e Túlio Alberto Martins de Figuereido. (Org.). Rizoma II: Saúde coletiva \& Instituições.2. ed. Jundaí: Paco Editorial. 2018, v. 2. p. 127-150

LIBÂNEO, J. C. Pedagogia e pedagogos, para quê?. 8. ed. São Paulo: Cortez, 2005.

LIMA, Joana Azevêdo; ALBERTO, Maria de Fátima Pereira. O Olhar de Mães acerca do Abuso Sexual Intrafamiliar Sofrido por suas Filhas. Psicol. cienc. prof., Brasília, v. 35, n. 4, p. 1157-1170, 2015. Disponível em: <http:// www.scielo.br/scielo.php?script=sci_arttext\&pid=S1414-98932015000401157\&lng=en\&nrm=iso $>$. Acesso em: 12 Mar. 2020.

MATIAS, Virgínia Coeli Bueno de Queiroz. Cúmplices do silêncio: a ausência de uma prática pedagógica que desconsidera a sexualidade e a violênciasexual.PUCMINAS.

MEDEIROS, Simone Alves de; CARVALHO, Andréia Cristina dos Santos; SILVA, Eloísa Machado da. A escola como espaço de prevenção da violência sexual. Simpósio, [S.1.], n. 7, fev. 2019. ISSN 2317-5974. Disponível em: $<$ http://revista.ugb.edu.br/index.php/simposio/article/view/1276>. Acesso em: 27 abr. 2019.

NAKATANI, Fabiana Massako. Abuso sexual intrafamiliar contra a criança: entre o direito e a psicologia. Monografia de conclusão de curso (Bacharel em Direito), Universidade Federal do Paraná. Curitiba, 2012.

PEREIRA, Ricardo. O trabalho do Pedagogo Social com Famílias em Situação de Vulnerabilidade Social: elementos para o debate. Journal of Social Pedagogy, [S.1.], v. 6, n. 2, 2018. Disponível em: $<$ http://www.revistadeped- 
agogiasocial.uff.br/index.php/revista/article/view/143>. Acesso em: 27 abr. 2019.

PLATT, Vanessa Borges et al. Violência sexual contra crianças: autores, vítimas e consequências. Ciênc. saúde coletiva, Rio de Janeiro, v. 23, n. 4, p. 1019-1031, 2018. Disponível em: <http://www.scielo.br/scielo.php?script=sci_arttext\&pid=S1413-81232018000401019\&lng=en\&nrm=iso>. Acesso em: 12 Mar. 2020.

Resolução $n^{\circ} 17$ de 20 de junho de 2011. Ratificar a equipe de referência definida pela Norma Operacional Básica de Recursos Humanos do Sistema Único de Assistência Social - NOB-RH/SUAS e Reconhecer as categorias profissionais de nível superior para atender as especificidades dos serviços socioassistenciais e das funções essenciais de gestão do Sistema Único de Assistência Social - SUAS. Diário Oficial [da] República Federativa do Brasil, Brasília, DF, 21 jun. 2011. Disponível em: Acesso em: 01 maio 2019. 